\title{
Educação e desenvolvimento: cultivando a humanidade nas esferas da sociedade civil
}

\author{
Manuel Gonçalves Barbosa*
}

\section{RESUMO}

\begin{abstract}
Este artigo, tendo por referência o clima de ansiedade econômica que se vive na Europa, revisita o tema da educação e do desenvolvimento e defende que a sociedade civil, por meio das suas instituições e organizações, pode desempenhar um interessante papel na promoção de um outro desenvolvimento, não propriamente como reincidência no aumento do produto interno bruto e na visão utilitária das pessoas, mas como cultivo de uma humanidade que hoje se confronta, em todo o lado, com preocupantes desafios nas áreas da governação, da cultura, dos direitos humanos, da justiça e das relações com o meio ambiente.
\end{abstract}

Palavras-chave: Educação. Desenvolvimento. Sociedade civil.

\section{Introdução}

A educação e o desenvolvimento andam de mãos dadas há muito tempo e não é de hoje que se apela a um estreitamento de laços entre as duas áreas. Vamos defender, mais adiante, que essa aproximação passa por resgatar e aproveitar o potencial educativo da sociedade civil em prol do desenvolvimento e que essa é uma questão pendente e verdadeiramente incontornável, tanto da ação política como da reflexão pedagógica. Entretanto, importa sublinhar que a educação não é patrimônio da escola e não ocorre apenas nos seus espaços. Outras instâncias e outros âmbitos participam nessa missão, induzindo comportamentos, desencadeando atitudes e fixando sistemas de valores. Essas instâncias e esses âmbitos dão forma a uma rica tapeçaria de agentes educativos que não podemos ignorar, seja porque condicionam enormemente a socialização primária, seja porque ajudam a reconfigurar subjetividades ao longo de uma vida.

Recebido: 23/09/2013 - Aprovado: 06/12/2013

http://dx.doi.org/10.5335/rep.v21i1.3871

Doutor em Educação pela Universidade do Minho-Portugal e atualmente Professor Associado no Departamento de Teoria da Educação e Educação Artística e Física do Instituto de Educação da Universidade do Minho. Membro Integrado do Centro de Investigação em Educação da Universidade do Minho. E-mail: mbarbosa@ie.uminho.pt. 
Os agentes educativos em questão têm a sua morada nas esferas da sociedade civil e aparecem ora como redes de associativismo voluntário, ora como redes ou espaços de relações intensas e mutuamente procuradas pelos indivíduos nas áreas da família, da fé, do interesse e da ideologia. Contam-se, entre esses agentes, as associações culturais, desportivas e recreativas, as organizações cívicas, os grupos religiosos, as famílias, os grupos de entreajuda e de solidariedade, os clubes de fãs, os grupos desportivos, as associações ambientalistas, os grupos étnicos, os movimentos sociais e uma grande panóplia de organizações não governamentais.

O desenvolvimento não pode passar sem o concurso de todos esses agentes, na medida em que é concebido como cultivo da humanidade nas circunstâncias presentes, e não como mero crescimento econômico, tal como se reativa, hoje, nos cenários de recessão ou estagnação, designadamente nos países componentes da União Europeia.

Assistimos, nesses cenários, a uma situação paradoxal no que concerne à educação e ao desenvolvimento: por um lado, e com toda a pompa e circunstância, proclama-se aos quatro ventos que a educação deve promover o desenvolvimento e que este deve ser integral e multidimensional, focalizado nas pessoas e na atualização de todo o seu potencial; mas, por outro lado, e em clara dissonância com essa retórica, tudo converge para recentrar a promoção do desenvolvimento no aumento da riqueza material, nos ganhos de produtividade, na valorização e na acumulação do capital, ou seja, no progresso econômico medido em termos de produto interno bruto per capita.

O clima de ansiedade econômica que hoje se vive na Europa não ajuda a ver o paradoxo, mas o fato é que ele existe e já origina dissensões paradigmáticas quanto às visões da educação e do desenvolvimento, correndo mesmo o risco de desviar-nos da ideia de cultivo da humanidade que a educação e o desenvolvimento precisam acalentar para dar futuro ao futuro humano com o inestimável contributo da sociedade civil organizada.

Depois de discutir as dissensões paradigmáticas acerca da educação e do desenvolvimento que fraturam os cenários sociais europeus e de resgatar, em segundo lugar, o potencial da sociedade civil em termos de promoção de uma educação para um desenvolvimento entendido como cultivo da humanidade, o nosso propósito é ir ao encontro das alíneas pelas quais se pode reger, com incentivos estatais, uma agenda educativa da sociedade civil visando às disposições, às capacidades e aos valores de que o ser humano precisa para enfrentar com empenho e lucidez os desafios atuais. 


\section{EDUCAÇÃO E DESENVOLVIMENTO: DISSENSÕES PARADIGMÁTICAS EM TEMPOS DE CRISE}

As dissensões paradigmáticas acerca da educação e do desenvolvimento não são de hoje e sequer constituem uma especificidade europeia. Sobre educação e desenvolvimento há posições divergentes que remontam, pelo menos, aos anos que se seguiram à segunda guerra mundial, e logo aí se vislumbraram dois caminhos: ou trilhar a senda do crescimento econômico como meta do desenvolvimento e tarefa subsidiária da educação, ou, então, apostar numa concessão integral e multidimensional de bem-estar humano como horizonte tanto da educação quanto do desenvolvimento.

A história nos diz que após o segundo grande conflito mundial prevaleceu, de maneira hegemônica e avassaladora, a perspectiva que colocou a educação e o desenvolvimento na linha da acumulação de riqueza material, do avanço tecnológico e do progresso econômico, tudo visando a cotas elevadas de consumo e conforto. O paradigma, abrangendo no mesmo arco a educação e o desenvolvimento, afirmava claramente os princípios da racionalidade econômica mais estrita e desconsiderava, por esse fato, outras variáveis que não as relativas ao aumento do produto interno bruto. O objetivo era o crescimento, e o crescimento media-se como progressão do PIB, quer dizer, "a progressão do volume de todas as produções de bens e serviços que se vendem, ou com preço monetário, produzidos pelo trabalho remunerado" (LATOUCHE, 2011, p. 48-49).

Os círculos internacionais ligados à promoção do desenvolvimento, nutridos pela experiência de três décadas das Nações Unidas para o desenvolvimento, e não contentes com essa visão excessivamente focalizada na prosperidade econômica, acabam por protagonizar, no início da década de 1990, uma inversão de perspectivas: desde o palco mundial das Nações Unidas e do seu Programa para o Desenvolvimento (PNUD) passam a defender, e a inscrever em sucessivos relatórios, que o paradigma orientador tem que ser outro, não mais o crescimento pelo crescimento, ou a "fixação economicista no primado do rendimento e da riqueza" (SEN, 2003, p. 35), mas a efetiva melhoria da qualidade de vida das pessoas, agora medida em termos de liberdade, democracia, segurança, igualdade de gênero, participação, direitos humanos e proteção do meio ambiente.

A partir dessa inversão paradigmática, e até muito recentemente, uma coisa parecia certa: o desenvolvimento, assessorado pela educação, elege as pessoas como centro, e pensa-se, no âmbito de programas e projetos comunitários, de maneira integral e multidimensional, de forma a abranger, em todo o lado, as componentes essenciais de uma vida digna e decente. 
Aquilo que parecia certo e um dado adquirido, quer ao nível das ações e da assunção de medidas, quer ao nível da retórica e das intenções, deixou de sê-lo a partir de 2008 aproximadamente, altura em que se começa a assistir a um agravamento e a uma deterioração da situação econômico-financeira de importantes economias avançadas do Ocidente, designadamente, e, em grande medida, das economias da região europeia. Subitamente, e num clima de grande preocupação quanto ao futuro do Estado social e de sustentação das sociedades de bem-estar material, dá-se um volte-face nas perspectivas da educação e do desenvolvimento e um regresso ao passado. Um regresso que significou a retomada do "velho" paradigma do crescimento econômico enquanto modelo diretor e imaginário orientador quer da educação, quer do desenvolvimento.

$\mathrm{O}$ volte-face paradigmático, na região europeia, é bem visível em vários documentos da Comissão Europeia, mas há um que é exemplar na cronologia e na terminologia: a "Estratégia Europa 2020", dado a lume em março de 2010 e ainda nesse ano rubricado pelo Conselho e Parlamento europeus. O objetivo da Estratégia, no meio de tantas ansiedades e incertezas quanto ao futuro da União, é claro e não deixa dúvidas: "Trata-se de uma agenda para todos os Estados-Membros, tendo em conta as diferentes necessidades, os diferentes pontos de partida e especificidades nacionais, a fim de promover o crescimento de todos" (COMISSÃO EUROPEIA, 2010, p. 12). A prioridade é, manifestamente, o crescimento, agora ressignificado como "crescimento inteligente", já que se trata de relançar e desenvolver "uma economia baseada no conhecimento e na inovação" (2010, p. 5). O que se quer é "uma União da inovação... para assegurar que as ideias inovadoras são transformadas em produtos e serviços que criam crescimento e postos de trabalho" (2010, p. 6). Visam-se a estratégias de retorno ao crescimento, e isso exige instrumentar a educação, sempre de mãos dadas com o desenvolvimento, no sentido desse crescimento:

Um crescimento inteligente significa reforçar o conhecimento e a inovação, enquanto fatores determinantes do nosso crescimento futuro. Para tal é necessário melhorar a qualidade da nossa educação, reforçar o desempenho da nossa investigação. Promover a inovação e a transferência de conhecimentos em toda a União, tirar plenamente partido das tecnologias da informação e da comunicação e assegurar a transformação das ideias inovadoras em novos produtos e serviços que criam crescimento e emprego de qualidade e que ajudam a enfrentar os desafios societais que se colocam a [sic] nível europeu e mundial (2010, p. 14).

O crescimento é o eixo articulador de toda a Estratégia e consubstancia-se, in fine, em crescimento essencialmente econômico, ainda que se diga que deve ser sustentável e inclusivo além de inteligente.

Com essa estratégia, e pelo período de uma década, a União dos 27 recoloca a educação e o desenvolvimento na linha direta do crescimento e prepara o terreno 
para uma mudança de fundo no que concerne à missão das instituições educativas, nomeadamente as de ensino médio e universitário. Aqui e ali, a mudança já é notória e verifica-se que passa, fundamentalmente, pelo recentramento da escola na norma da profissionalização e da empregabilidade. A escola, objeto de culto econômico e protagonista de uma nova narrativa, é pouco a pouco reordenada e reorientada conforme a finalidade profissional dos estudos. Na prática, isso passa por uma definição mais utilitária dos conteúdos de formação, com uma sobrevalorização das áreas científicas e técnicas; pela seleção dos estudantes por meio de dispositivos de orientação e acompanhamento, visando à inserção no mercado de trabalho; pela inculcação do espírito de empresa e pela centração economicista nas virtudes do empreendedorismo; pela multiplicação dos estágios em contexto laboral e pela definição estritamente profissional de livretes de competências como passaportes para o emprego.

Verifica-se, nesse espaço europeu novamente obcecado com o crescimento econômico, que a escola está em vias de reorganização curricular e que essa reorganização visa tão-somente à sua adequação aos imperativos desse crescimento por meio da construção de novas funcionalidades e de novas subjetividades. Por um lado, acentua-se a visão mercantil dos estudos e a relação instrumental com a escolaridade: "Trata-se menos de aprender do que gerir o seu percurso em função de imperativos econômicos" (LAVAL et al., 2011, p. 191). Por outro, opera-se uma relativização da missão de transmissão de saberes em ordem a favorecer, através da escola, "a fabricação de uma subjetividade mercantil" (2011, p. 184) e o acesso às competências congruentes com os objetivos do crescimento.

Os percursos escolares, a essa luz, já não são referidos a exigências de verdade e de construção conceptual, ou sequer à formação de cidadãos lúcidos e críticos em relação à sua situação, mas a uma racionalidade que invade todas as esferas da existência humana em sociedade: a racionalidade econômica.

Sob os auspícios dessa racionalidade, as instituições de educação e formação transformam-se num campo fértil de mercadorização de serviços ao cliente e assumem-se cada vez mais como lugares de acumulação de capital. Repentinamente, desinteressam-se da formação de cidadãos, ou de pessoas aptas para viverem em sociedade, capazes de escolher, julgar e controlar os seus representantes, e passam a investir em capital humano, ou seja, na produção de subjetividades acomodadas às exigências do "crescimento inteligente", num mundo de guerras econômicas e financeiras à escala global.

Num contexto como esse, e nas condições particulares da região europeia, a tentação é centrar a ação educativa no desenvolvimento do potencial econômico dos indivíduos e transformar as instituições com esse mandato em campo de treino, ora da empregabilidade, ora da reciclagem permanente. Como os desafios do 
crescimento passam hoje pelo investimento no conhecimento, ou seja, pelo capital imaterial, esse mandato deve produzir o novo homem conforme a economia do conhecimento, hoje rebatizada de "inteligente" pela Comissão Europeia (2010, p. 5).

A grande "casa" europeia, assediada pela guerra econômica global e em risco de ter que rever em baixa as expectativas em relação ao Estado social, aposta decisivamente no crescimento do produto interno bruto e, assim, contra a retórica que tem defendido, corre aceleradamente para a maximização do valor instrumental das pessoas, fazendo delas, nesta época de crise, meros recursos para as empresas. A crise está a servir de pretexto a essa visão restritiva das pessoas, quando as pessoas, devidamente consideradas, não são apenas esses recursos: "Os seres humanos não são meros meios de produção" (SEN, 2003, p. 302). São mais que capital humano ao serviço da economia e do crescimento econômico. Se é verdade que precisamos de pessoas preparadas para as atividades produtivas, ergo para 0 mundo do trabalho, e se não podemos ignorar que o crescimento, dentro de limites sustentáveis, pode ser imprescindível para o desenvolvimento humano, também é certo que as pessoas são fins em si mesmas, e não meros utensílios da economia. De resto, é preciso sublinhar que "não há vínculo automático entre crescimento e desenvolvimento" (PEDRAJAS; JORDÁN, 2009, p. 225). A assimilação do crescimento a uma elevação do bem-estar e, por maioria de razão, à felicidade é, segundo a expressão de Jean Baudrillard, "um extraordinário bluff coletivo... uma operação de magia branca" (1970, p. 42). O elevado crescimento econômico não se traduz, necessariamente, no bem-estar de todos: " $E$ falsa a ideia, mantida durante tantos anos, que associa crescimento econômico e bem-estar geral. As grandes bolsas de pobreza tiveram um crescimento espetacular ao mesmo tempo que se produzia um elevado crescimento econômico" (PRADOS; CALIXTO, 2008, p. 181). São necessárias medidas políticas concretas, e quase sempre corajosas, para traduzir o progresso econômico em progresso humano.

A verdadeira mudança, por conseguinte, há de passar por um novo conceito de crescimento econômico que favoreça a justiça e o autêntico desenvolvimento das capacidades das pessoas, não só de uns poucos, e que além disso não ponha em perigo a capacidade de regeneração do planeta. Apostar no crescimento pelo crescimento, assente na visão instrumental do ser humano e na apropriação intensa da natureza, é uma receita para o desastre. A região europeia, preocupada como está com o crescimento, pode muito bem resvalar para essa concessão e, assim, encurtar, na prática e em teoria, as perspectivas mais risonhas da educação e do desenvolvimento.

O risco de isso acontecer não é mera especulação, pois, no presente momento, já se verifica uma contradição entre as retóricas do desenvolvimento integral e multidimensional do ser humano, respeitador da sua integridade e da sua dignidade, e 
as novas agendas da educação, assentes no imaginário do crescimento econômico, da criação de riqueza e na maximização do valor utilitário dos indivíduos. A linha de fratura entre os paradigmas de educação e desenvolvimento é cada vez mais notória: de um lado, posicionam-se aqueles que tudo submetem à racionalidade econômica e à busca de rentabilidade, e do outro, aqueles que se comprometem com o respeito pelo ser humano. Neste lado da barricada, de maneira firme e empenhada, estão todos aqueles que defendem, como Marta Nussbaum (2007) e Amartya Sen (2003; 2007), a potenciação das liberdades humanas e das capacidades que, em várias esferas existenciais, tornam-se fundamentais para fazer opções e delinear planos de vida.

A promoção do desenvolvimento humano, com essa abrangência e com esse significado, é uma tarefa demasiado grande para ficar circunscrita à iniciativa de um só agente. De fato, para se realizar, precisa do concurso e das sinergias de vários agentes, entre os quais, para além das escolas e das agências estatais, encontram-se as organizações constitutivas da sociedade civil, tanto da esfera pública como da esfera privada. Um desenvolvimento com rosto humano e com as pessoas no centro (BARBOSA, 2006, p. 40), atento aos desafios societais atuais e às mudanças que é preciso realizar em termos de comportamentos e mentalidades, não se pode dar ao luxo de prescindir dos serviços das organizações e dos atores da sociedade civil. A promoção do desenvolvimento é, mais do que nunca, uma responsabilidade partilhada, e a sociedade civil, com o seu potencial educativo, pode dar um interessante contributo nesse sentido.

\section{EDUCAÇÃO, SOCIEDADE CIVIL E DESENVOLVIMENTO}

O desenvolvimento de que hoje precisamos, diante de desafios inéditos e preocupantes, como o aumento galopante da diversidade cultural, a dramática degradação dos ecossistemas, ou, ainda, as problemáticas da governação, da justiça e dos direitos humanos num mundo simultaneamente global e desigual, não pode ignorar as pessoas. São elas que, doravante, devem estar no centro do desenvolvimento. O desenvolvimento, para estar à altura desses desafios, tem que apostar nas pessoas, nos seus saberes, nas suas capacidades, nas suas competências e nos seus valores. O que verdadeiramente interessa é um desenvolvimento das pessoas, para as pessoas e com as pessoas.

$\mathrm{Na}$ verdade, esse é um refrão que se vai ouvindo um pouco por todo o lado, nomeadamente nos círculos internacionais dedicados à promoção do desenvolvimento, como é o caso da Organização das Nações Unidas e, em parte, do Banco Mundial e de suas dependências. Contudo, a prática está longe da retórica. Um 
longo caminho precisa ser trilhado para focalizar o desenvolvimento nas pessoas, e não no crescimento do produto interno bruto, no aumento da receita, na industrialização, na informatização, no avanço tecnológico ou na modernização institucional. Um desenvolvimento centrado nas pessoas e, portanto, com rosto humano, vai além dessas alíneas. É um compromisso mais amplo, não só com as bases materiais da qualidade de vida e, obviamente, com a sua preservação no seio do ecossistema, mas também, e sobretudo, com valores e aspirações que são centrais a uma vida decente e digna: a liberdade, os direitos humanos, a democracia, a paz, a segurança, a justiça, o direito às tradições e à cultura própria, o reconhecimento, a participação nas instituições que dão forma à vida comunitária, a civilidade entre todos e a convivialidade no mesmo espaço.

Os seres humanos, como mostram à exaustão os sucessivos relatórios sobre desenvolvimento humano do Programa das Nações Unidas para o Desenvolvimento, não valorizam apenas a satisfação de necessidades básicas que o dinheiro pode comprar: uma boa nutrição, água potável, serviços médicos, habitação condigna e ensino para os filhos. Valorizam, também, e sem qualquer surpresa, a imaterialidade de valores que dão respiração, orientação e sentido à vida. A conclusão de Amartya Sen, nesse particular, não podia ser mais taxativa: "As pessoas têm sem dúvida necessidades, porém, também têm valores... Visualizar as pessoas unicamente em função das suas necessidades poderia transmitir uma visão bastante limitada da humanidade" (2007, p. 54).

O desenvolvimento como cultivo da humanidade não discute a relevância das variáveis econômicas na qualificação da vida humana e muito menos a importância da sustentabilidade. Discute, isso sim, a redução do desenvolvimento a variáveis econômicas e a uma ideia de sustentabilidade que se reporta, única e exclusivamente, à satisfação de necessidades básicas, tanto das gerações presentes como das futuras. Mais além do preenchimento de necessidades básicas, o desenvolvimento que aqui defendemos, e que se traduz no cultivo da humanidade, aponta para os valores e as aspirações atrás recenseados. Esse é o horizonte do cultivo da humanidade, e a educação, enquanto poderoso fator de capacitação das pessoas para aquilo que mais apreciam e valorizam, é uma área incontornável, seja nos espaços formais das escolas e das universidades, seja nos ambientes não formais e informais dos vários setores sociais, designadamente nas organizações constitutivas da sociedade civil.

A educação, na verdade, está umbilicalmente comprometida com o desenvolvimento humano e não poderia renunciar a isso sem se contradizer. O seu imaginário é o desenvolvimento humano. A ele se entrega de maneira formal, não formal e informal, e sempre supraditada por orientações axiológicas. Hoje, no quadro dos novos desafios, a tarefa da educação é enorme e não poderia ser realizada sem o con- 
curso de vários agentes, não só da escola e de instituições similares, mas também, e em boa parte, da rica tapeçaria de organizações que compõem a sociedade civil. A educação não se confina às escolas, e a responsabilidade de educar está longe de esgotar-se nas instituições escolares. Se queremos a educação como alavanca do desenvolvimento humano, e se este há de consistir, no presente momento, na capacitação das pessoas para valores pós-materialistas, então, deixemos de sequestrar a educação nas escolas, de fazê-la refém de espaços e de agentes manifestamente insuficientes na ignição de atitudes, na modelação de comportamentos e na transformação de mentalidades. Não se peça à escola o impossível, pois "não é a escola sozinha que se deve ocupar de questões que dizem respeito a toda a sociedade" (CAMPS, 2010, p. 161). Porque a responsabilidade é de todos, importa reservar um lugar para a sociedade civil no cultivo da humanidade, não obstante a controvérsia em torno do seu significado e de não poder assegurar, em todas as suas esferas, determinadas normas e determinados valores (PIROTTE, 2007, p. 54).

A sociedade civil é um significante de pluralidade, e isso quer dizer, em condições de crescente diferenciação social, que a sociedade civil estrutura-se como conjunto diversificado, e por vezes contraditório, de grupos, movimentos e associações. O âmbito da sociedade civil, mais ou menos dilatado conforme os quadros políticos de referência e as práticas institucionalizadas dos seus atores, configura tanto a solidariedade e a cooperação como a disparidade e a fragmentação. A sociedade civil é "o reino da fragmentação e da luta, mas também de solidariedades concretas e autênticas" (WALZER, 1998, p. 16). Nas suas esferas, "andam de mãos dadas a racionalidade estratégica e a comunicativa, a competição de interesses e a cooperação, o individualismo egoísta e a solidariedade" (CORTINA, 1998, p. 192). Se, por um lado, dá aos indivíduos a oportunidade de cooperarem em defesa de interesses comuns, por outro, coloca-os em rota de colisão quando autoriza a prossecução de interesses divergentes e contraditórios tanto nas esferas públicas como privadas.

A sociedade civil, não obstante a confusão e a ambiguidade a propósito do seu significado, é um valor bem cotado nas estruturas conceptuais do pensamento político contemporâneo. Renasceu em grande escala nas décadas de 1980 e 1990 e pode dizer-se, sem grandes exageros, que se tornou a vedeta do pensamento em torno da sociedade e da política. Há, certamente, um largo consenso acerca da sua importância, mas há, igualmente, um crescente desacordo sobre o seu sentido exato. "Há mesmo sinais", diz-nos J. Keane, "de que os sentidos da expressão 'sociedade civil' estão a multiplicar-se a um ponto tal que, como uma frase publicitária que chama a atenção, ela se arrisca a implodir devido ao excesso de uso" (2001, p. 49).

A linguagem em torno da sociedade civil é cada vez mais confusa, tem diferentes regras de gramática e, o que é pior, remete frequentemente para vocabulários contraditórios. Por isso, como reconhece Olvera, "falar de 'uma' sociedade civil... 
é problemático" (2003, p. 412), pois a expressão faz referência, aqui e agora, a uma grande variedade de associações, grupos, instituições, atores, movimentos, todos marcados por uma grande diversidade de objetivos e pontos de vista acerca do que deve ser uma sociedade 'boa'. Seja como for, algumas consensualidades se têm construído em torno dessa matéria: longe de corresponder a uma visão abrangente e totalizadora, onde se incluem as esferas política, econômica e social, tanto no que toca às normas como às instituições e aos atores, a sociedade civil afirma-se hoje, essencialmente, como uma realidade formada por redes de associativismo voluntário, quer em esferas públicas, quer em esferas privadas, abrangendo as áreas da família, da fé, do interesse e da ideologia e resultando, em todo o lado, da capacidade auto-organizativa dos seres humanos.

Essas consensualidades, ou convergências, colocam a sociedade civil entre 0 indivíduo e o Estado (REQUENA, 2008, p. 33) e distinguem-na, na maioria dos casos, da esfera econômica e do mercado. Ou seja, o que predomina hoje é uma visão associativa e auto-organizativa da sociedade civil, tanto à margem do mercado como do Estado, bem na linha da valorização tocquevilliana da associação espontânea dos cidadãos. Isso é reconhecido por um especialista na matéria, fazendo a síntese das ideias comumente aceitas:

Originariamente, a expressão "sociedade civil" refere-se a um tipo de sociedade, e inclui tanto o estado como os mercados e o tecido associativo. Com o tempo, deu-se um deslocamento semântico, mediante o qual a sociedade civil passou a significar "o que não é estado" (mercados e associações) ou a reduzir-se a associações. Hoje em dia, é muito frequente que na comunidade acadêmica, política e mediática se use a sociedade civil como sinônimo de associações ou tecido associativo (PÉREZ-DIAS, 2008, p. 222).

Os usos sociais da noção de sociedade civil são plurais e não se pode esconder que há apropriações ideológicas dessa noção. A promoção mediática da sociedade civil nem sempre se articula com um projeto de emancipação coletiva e, portanto, com uma aposta em novas ideias e novos valores. Ainda assim, é importante reconhecer o seu protagonismo na educação e na formação das pessoas e o apoio que pode dar à promoção do desenvolvimento humano, aqui semantizado e escrutinado como cultivo da humanidade.

Mesmo sem chegar ao ponto de afirmar que a civilidade só pode ser aprendida nas redes associativas e relacionais da sociedade civil (WALZER, 2010, p. 197), é um fato que esta contribui enormemente para nos tornarmos homens e mulheres sociáveis e comunitários. Nas organizações da sociedade civil, aprendemos a viver juntos, a respeitar regras e a desenvolver os nossos talentos de seres humanos. "Todas as associações desenvolvem as suas próprias disposições normativas e fazem a promoção de valores e comportamentos que julgam os mais adequados" (PIROTTE, 2007, p. 54). 
Há todo um potencial educativo a explorar nas arenas da sociedade civil, primeiro pelo trabalho hermenêutico da reflexão pedagógica e, depois, pelas iniciativas da ação política, visando estas a incentivos e recompensas a todas as organizações que se comprometam com os objetivos do desenvolvimento humano. Com efeito, não basta assinalar que as organizações da sociedade civil são uma peça-chave na promoção do desenvolvimento, como de fato vem acontecendo desde os anos 1980 e 1990, e isso tanto pela Comissão Europeia (2001) como pela Unesco (2005), ou pelo FMI e o Banco Mundial, na sequência da adoção do paradigma de desenvolvimento participativo como novo referente da ajuda ao desenvolvimento. Se nas três décadas que se seguiram à segunda guerra mundial a noção de sociedade civil esteve ausente da reflexão sobre os caminhos do desenvolvimento, já por volta dos anos 1990, a mesma noção torna-se uma peça verdadeiramente central, para não dizer indispensável, das políticas de desenvolvimento tal como foram concebidas e orquestradas pelas agências internacionais.

A sociedade civil, libertando-se do poder sufocante do Estado e da sua tendência para castrar as suas iniciativas, ainda que colaborando com ele nas parcerias do desenvolvimento e da educação para o desenvolvimento, designadamente por meio de associações e ONGs, começa a ter o reconhecimento que merece, não obstante os perigos de instrumentalização a que está sujeita, quer por parte dos agentes do Estado, quer por parte do mercado.

A sociedade civil não é a única depositária do bem público (OTAYEK, 2007, p. 147) e sequer é um poço de virtudes. "Não devemos esperar tudo de todo o tipo de associações da sociedade civil" (WARREN, 2004, p. 89). Ainda assim, e na atualidade, face à necessidade de alavancar, desde as suas esferas, o cultivo da humanidade, importa resgatar e valorizar o seu potencial, nomeadamente aquele que "pode chegar a modificar profundamente a vida pessoal mediante a transformação de certos estilos de vida e pautas de comportamento" (TEJERINA, 2005, p. 89).

Não há que esperar revoluções extraordinárias das organizações da sociedade civil em termos educativos, porém, estas sempre podem contribuir para o cultivo da humanidade que é hoje confrontada com novos e angustiantes desafios, seja na área da cultura e das relações humanas, seja no domínio mais circunscrito da interação com a biosfera. É, certamente, importante que nos desembaracemos das visões ingênuas e monolíticas de sociedade civil e, em particular, das concessões dualistas que a colocam em alternativa com o Estado. Em questões de desenvolvimento e, por maioria de razão, de desenvolvimento humano, nem a sociedade civil substitui o Estado nem o Estado, a sociedade civil. Se um dispõe de capacidade legislativa e de poder administrativo para orientar esse desenvolvimento pelo bom caminho, além de recursos que outras entidades não têm, a outra dispõe de capaci- 
dade de influência nas agendas do desenvolvimento e uma força nada despicienda na sedimentação de valores e na produção de comportamentos.

Só por esse fato, a sociedade civil deveria merecer toda a nossa atenção em matéria educativa. A sua contribuição para o desenvolvimento como cultivo da humanidade é necessária e bem-vinda, mas não de qualquer maneira, ou sem orientação, pois, como já vimos, a sociedade civil não é necessariamente virtuosa, “também pode brilhar pela sua incivilidade" (OTAYEK, 2000, p. 126). Sendo assim, justifica-se assentar na ideia de uma agenda educativa da sociedade civil que, desde baixo, dê o seu impulso ao cultivo da humanidade nas circunstâncias presentes.

\section{CULTIVANDO A HUMANIDADE NAS ESFERAS DA SOCIEDADE CIVIL: ALÍNEAS DE UMA AGENDA EDUCATIVA}

A questão que agora se coloca, à luz da revalorização pedagógica da sociedade civil e da identificação, não menos importante, das suas responsabilidades educativas, pode ser assim formulada: de que modo a sociedade civil, nas atuais circunstâncias, pode apoiar o cultivo da humanidade a partir das suas esferas? Que papel assumiria para si num quadro diverso e complexo de desafios que passam pelas áreas da governação, da cultura, dos direitos humanos, da justiça e das relações com a natureza? Ou seja, que alíneas integrariam a sua agenda educativa tomando por referência esses desafios?

O que está em causa, pela sua dimensão ou envergadura, não está apenas cometido à sociedade civil, e a sua intervenção, ou protagonismo, será eventualmente mais profícua não em todas, mas em certas áreas. Seja como for, alguma ação precisa ser realizada no âmbito das suas responsabilidades educativas, e estas, a serem congruentes com esse elenco de desafios, passariam, entre outras alíneas, por estímulos à cidadania democrática e à cidadania ecológica, ao convívio e à interação dialógica com a alteridade cultural, à imaginação narrativa, à visão cosmopolita e a um renovado sentido de justiça.

O estímulo à cidadania democrática, nas arenas intersubjetivas da sociedade civil, justifica-se por dois motivos: por um lado, para envolver os cidadãos nas novas modalidades de governação dos assuntos comuns, hoje mais descentralizadas e mais próximas das coletividades; por outro, para reconstruir a democracia como projeto de vida em comum, baseado no respeito da liberdade, da igualdade e da solidariedade.

Antes de tudo, o estímulo ou o incentivo ao envolvimento em novas formas de governação derivadas da impossibilidade de os Estados corresponderem, sozinhos, às crescentes demandas sociais e da sua incapacidade de afrontar, com os seus recursos, os desafios emergentes nas áreas da gestão dos territórios, como, por 
exemplo, as cidades. Uma dessas novas formas de governação é a "governança democrática", a qual é hoje patrocinada, em solo europeu, pela Comissão Europeia. Essa comissão tem vindo a promover a governança como modo de governar baseado na horizontalidade e na concertação, e isso tem que ver não apenas com a prática de um governo supranacional que precisa articular os interesses de diferentes governos dos Estados-nação, mas também com a necessidade de incorporar os governos regionais, locais e a própria sociedade civil na construção da Europa. De acordo com o Livro Branco sobre Governança Europeia, elaborado pela Comissão Europeia em 2001, o conceito de governança abrange cinco princípios básicos: abertura, participação, responsabilidade, eficácia e coerência. Os princípios, segundo a filosofia desse documento, têm em vista fortalecer a relação da UE com a sociedade civil e um maior uso das capacidades dos atores regionais e locais em estabelecer as bases de uma clara definição dos objetivos políticos da UE e centrar os papéis e as responsabilidades de cada instituição. A governança, nesse sentido, associa-se diretamente com uma aposta de governo pela descentralização, a participação cidadã e a colaboração da sociedade civil.

A governança democrática, com esse contributo da Comissão Europeia, é hoje entendida como nova arte de governar os territórios visando ao desenvolvimento humano, assente na participação dos cidadãos, no fortalecimento dos valores cívicos, na revalorização da política democrática e na construção coletiva do interesse geral. Como refere P. Esteve,

A governança democrática é uma nova forma de governar o território que dá prioridade a dois temas: a articulação e complementaridade de atuações públicas e privadas em projetos de ação com objetivos comuns (projetos em rede) e a responsabilização e envolvimento dos cidadãos em temas de interesse geral (2011, p. 290).

Esses temas relacionam-se com a gestão urbana, os cuidados de saúde ou, mesmo, a educação. Assim, o incentivo à cidadania democrática desde as esferas da sociedade civil ganha relevo e importância, pois, sem ela, dificilmente encontraremos sustentação para essa nova forma de governação a que se chama, presentemente, governança democrática.

O incentivo à cidadania democrática, numa segunda análise, justifica-se pela necessidade de reconstruir, hoje em dia, a própria democracia como projeto de vida em comum (ROSANVALLON, 2011) assente nos valores da liberdade, da igualdade e da solidariedade. Da liberdade, como potencialidade de fazer aquilo que mais valorizamos na vida (SEN, 2003, p. 71); da igualdade ou da mesma dignidade de todos os seres humanos; e da solidariedade como compromisso cívico em relação à defesa das vítimas do não reconhecimento, da exclusão, da indecência e da humilhação. 
Igualmente importante para a vida em comum, e mais ainda para a sua sustentabilidade, é o apoio que a sociedade civil pode dar à cidadania ecológica por intermédio de associações ambientalistas e de organizações não governamentais que se destacam nessa área. Além de cidadãos ativos e participativos nas novas formas de governação, as sociedades, na era dos problemas ambientais globais e da “crise ecológico-planetária" (LIMÓN, 2007, p. 110), também precisam de cidadãos conscientes desses problemas, dessa situação e dispostos a colocarem o seu grão de areia na empresa coletiva de se conseguir a sustentabilidade ambiental.

Além da reivindicação do direito a um meio ambiente adequado para a saúde e o bem-estar, sempre importante e indispensável, o cidadão ecológico ou ambiental, encorajado pela sociedade civil e dela colhendo os bons exemplos, estaria, sobretudo, preocupado com o bem comum da sustentabilidade, e isso tanto em nível local como global, já que os problemas ambientais atuais, verdadeiramente sérios, não têm barreiras nem fronteiras. Uma cidadania ecológica articulada em torno desse objetivo estaria, segundo Dobson (2010, p. 155), mais centrada nas responsabilidades do que nas prerrogativas ambientais, ou seja, nos direitos. Assim, o que se exigiria ao cidadão ecológico, a esse cidadão que a sociedade civil também ajuda a construir nas suas esferas, é que não comprometa a capacidade de outras gerações, presentes ou futuras, e não só do seu país, de realizarem opções valiosas e de viverem uma vida significativa. Se há uma obrigação para o cidadão, ambiental ou ecológico, essa obrigação só pode ser, diante da defesa da sustentabilidade, a redução dos impactos no ecossistema, e isso enquanto se produz e reproduz a vida diária, seja no domicílio, seja nos lugares públicos. Dessa forma, educar para a cidadania ecológica é educar para assumir responsabilidades tanto em relação ao presente, quanto em relação ao futuro, é ir além de territórios bem delimitados, como a esfera privada e o próprio país, e é ainda uma ação de conscientização visando ao conhecimento e à mobilização para a defesa dos valores ambientais.

A sociedade civil, através dos seus atores e das suas organizações, não garante, em todo o lado, esse tipo de educação, como, aliás, não assegura, a priori, os incentivos à cidadania democrática. Ainda assim, sabemos que ajuda a enfrentar os desafios ambientais atuais, e isso já é reconhecido, inclusive, no Documento Final da Unesco sobre a Década da Educação para o Desenvolvimento Sustentável, quando é cometido à sociedade civil a tarefa de promover valores, como: "respeito e cuidado pela grande comunidade da vida, que inclui proteção e restauração dos ecossistemas da Terra" (2005, p. 43), ou, ainda, e tendo em conta esses valores, "estimular a sensibilização dos cidadãos, organizar atividades de promoção, campanhas e grupos de pressão" (2005, p. 70). 
Assim como precisamos da sociedade civil para nos prepararmos para os desafios ambientais, também carecemos dela para afrontarmos os presentes desafios culturais, devido a um crescimento exponencial, e talvez nunca antes visto, da diversidade cultural. Esse é um desafio bastante delicado e passa, antes de tudo, pelo respeito e reconhecimento de quem diverge de nós em língua, tradições, costumes e religiões.

Também aqui, a sociedade civil tem um contributo a dar. Essa contribuição, de especial interesse na era das afirmações e das tensões identitárias, passaria por dar estímulos ou incitamentos, desde as suas esferas, ao convívio e à interação dialógica com a alteridade cultural, especialmente aquela que surge como mais estranha e mais difícil de compreender nos cenários multiculturais atuais, ou seja, nos espaços urbanos (BARBOSA, 2011) e nas cidades globais (SASSEN, 1999).

A disposição para a interação dialogante e o convívio com a alteridade cultural, por não estar enquadrada em dispositivos normativos, está fundamentalmente dependente dos incentivos da sociedade civil. São os estímulos da sociedade civil, desde as redes relacionais da família aos espaços abertos da esfera pública, passando por redes de sociabilidade no interior de grupos e associações, que em boa e significativa medida despoletam nas pessoas a vontade de dialogar e conviver com estranhos culturais. O convívio, na prática, só pode acontecer na base da interação dialógica, e esta, sob a forma de conversação honesta e civilizada, simétrica e igualitária, sem receios e medos, aberta aos mútuos questionamentos e à aceitação, como condição básica, "de que é possível procurar juntos a verdade e a justiça" (TODOROV, 2008, p. 285), muito depende das instituições da sociedade civil. Uma conversação assumida e valorizada pelas instituições da sociedade civil ajuda a compartilhar o espaço social com pessoas de identidades diferentes, a aprender com elas e a construir uma base de entendimento mútuo, inclusive quando abundam as discrepâncias:

A conversação entre diferentes identidades - entre diferentes religiões, raças, etnias e nacionalidades - vale a pena porque permite aprender das pessoas que têm ideias diferentes, inclusive incompatíveis com as nossas. E também vale a pena porque, se aceitamos a ideia de que vivemos num mundo com diversas pessoas e nos propomos conviver com elas em respeitosa paz, necessitaremos de nos entender mutuamente, inclusivamente se não estamos de acordo (APPIAH, 2008, p. 20-21).

A conversação, segundo esse autor (2007, p. 124), não é apenas um diálogo ou uma simples conversa. É, essencialmente, uma metáfora da inclusão na experiência e nas ideias dos outros. O mais importante da conversação não é o consenso ou a conversão desses outros às nossas perspectivas; é, antes, a aproximação que pode gerar entre estranhos culturais no seio das sociedades multiculturais. Como menciona Appiah, "basta que contribua para que as pessoas se acostumem umas às outras” (2007, p. 124). 
A imaginação narrativa, entendida como "capacidade de pensar como seria estar no lugar de outra pessoa, de interpretar com inteligência a história dessa pessoa e de entender as suas emoções, desejos e aspirações" (NUSSBAUM, 2010, p. 132), também se pode revelar importante para aproximar os estranhos entre si, nomeadamente por razões culturais, e seria uma pena que não fizesse parte da agenda educativa da sociedade civil, já que as suas organizações, clubes e associações possuem interessantes recursos para promover esse tipo de evento, como sejam as que cultivam a expressão dramática, mesmo amadora, a dança e a música, na medida em que essas expressões ajudam a comunicar, a abrir o diálogo, a colocar-se no lugar da outra pessoa, a compreender o seu mundo, as suas emoções, os seus sentimentos e as suas frustrações. São expressões que a sociedade civil já cultiva, nomeadamente para fins recreativos e ocupacionais, mas que agora pode cultivar com a intenção de potenciar, nas suas esferas, a imaginação empática ou narrativa.

O cultivo da humanidade, visando à convivialidade e à interculturalidade nas arenas sociais multiculturais, passa hoje pela promoção da imaginação narrativa e, ainda, pelo estímulo a uma visão cosmopolita, ou seja, a uma nova forma de ver os outros, nem só como iguais, nem só como diferentes, mas simultaneamente iguais e diferentes. A essa forma de encarar os outros, sem ênfase essencialista na diferença e sem dissolução, dessa mesma diferença, no céu estrelado do universalismo abstrato, podemos chamar, com Beck, "olhar cosmopolita" (2005, p. 71).

O olhar cosmopolita, sendo alínea da agenda educativa da sociedade civil, quer dizer que se procura temperar, desde as suas esferas, o respeito pela diferença (o outro é diferente e posso aprender com as suas diferenças) com o respeito pelos seres humanos enquanto humanidade comum, com os mesmos desejos, os mesmos temores e as mesmas aspirações. Por meio desse olhar, "as diferenças não são nem eliminadas nem ordenadas hierarquicamente, antes são aceitas como tais, valorizadas positivamente" (BECK; GRANDE, 2006, p. 33). Sob os auspícios desse olhar ou visão, a diferença é esbatida, mas não é suprimida. Aceita-se a diferença sem a converter em algo absoluto. Assim, abrem-se canais à comunicação com o outro, ao seu reconhecimento e à sua integração nas redes de interação da sociedade, acabando com fissuras e dualismos ("nós aqui, os outros ali") manifestamente empobrecedores e comprometedores da sã convivência entre estranhos culturais.

A nova forma de ver os outros, pautada na igualdade e na diferença, educa-se ao longo da vida, e essa é uma tarefa que assenta bem nas instituições da sociedade civil, não tanto por meio de retóricas e exposições, mas da prática diária e do exemplo, especialmente dos mais velhos. Uma sociedade civil que se preze, ciente das suas responsabilidades educativas, não descarta essa dimensão da educação, como, aliás, não enjeita o estímulo quotidiano a um renovado sentido de justiça. Antes de 
tudo, relativamente a um desenvolvimento que se quer socialmente justo, orientado pelo bem-estar de todos os seres humanos e pela potenciação das capacidades que são essenciais a uma existência digna (NUSSBAUM, 2007, p. 88-89), como ter uma vida longa e saudável, ser instruído, ter um nível de vida decente e gozar de liberdades cívicas e políticas para participar no cotidiano da sua comunidade (PNUD, 2003, p. 28). Depois, um renovado sentido de justiça pelas condições ambientais que todos precisam de usufruir e, aqui, tratar-se-ia da "justa distribuição do espaço ecológico" (DOBSON, 2010, p. 172) para produzir e reproduzir a vida de acordo com padrões aceitáveis e sustentáveis. Finalmente, o novo sentido de justiça passaria, nos contextos multiculturais, pela justiça cultural, ou seja, pela liberdade de expressar e cultivar a cultura própria, sempre que as práticas culturais sejam compatíveis com os direitos individuais fundamentais e nomeadamente com os critérios da "justiça democrática" (GUTMANN, 2008, p. 17), isto é, em síntese, com a igualdade perante a lei, a igualdade de liberdades e a igualdade de oportunidades.

Os bons ofícios da sociedade civil, não obstante as suas limitações e os seus enviesamentos, são necessários à implementação dessa agenda do desenvolvimento humano. Prescindir da sociedade civil, depois de se reconhecer que é, "direta ou indiretamente, uma força potente na educação das comunidades" (UNESCO, 2005, p. 90), seria uma pena e, no mínimo, contraditório.

\section{CONSIDERAÇÕES FINAIS}

A educação, nas suas diferentes modalidades, é uma alavanca do desenvolvimento, e este, nas circunstâncias atuais, precisa ser concebido como cultivo da humanidade e determinado por valores que preservem a vida e as liberdades de modo sustentável. A responsabilidade pelo cultivo da humanidade também inclui a sociedade civil, e esta, desde as suas esferas públicas e privadas, pode ser de grande ajuda na implementação de uma agenda educativa cujos tópicos, a título meramente indicativo e exploratório, encontram-se definidos na malha discursiva da última seção.

A sociedade civil, como vimos, não é a única depositária do bem público e, em questões educativas, não pode ser abandonada à sua sorte, especialmente se está em causa o cultivo da humanidade nos termos que o concebemos anteriormente. A sociedade civil tem os seus limites. A família, por exemplo, pode ser "uma esfera opressiva e violenta" (KALDOR, 2003, p. 49), dominada pelo imaginário machista, refém de assimetrias de poder e um caldo de cultura das desigualdades mais infames, entre adultos e entre adultos e crianças. Os grupos étnicos e religiosos, por sua vez, podem induzir o ódio ao estrangeiro (xenofobia) e a intolerância entre os 
fiéis de vários credos, inviabilizando, desse modo, o respeito pelas diferenças, a colaboração em projetos comuns, a confiança, a reciprocidade e os direitos iguais para todos. Por outro lado, não é garantido que a sociedade civil assegura os incentivos à cidadania democrática e à cidadania ecológica, pois nem sempre evidencia preocupações ambientais e não se rege, necessariamente, por princípios democráticos: "É evidente que as associações não são todas democráticas. Há algumas que alimentam injustiças, e até se esforçam em socavar as bases do sistema democrático" (LAVILLE, 2010, p. 22). Sendo assim, a idealização sem nuances da sociedade civil merece ser criticada, e não é por aí que se resgata o seu interessante contributo em termos de cultivo da humanidade, visando a valores pós-materialistas e à sustentabilidade, quer da sociedade, quer do ecossistema.

Uma operação de revalorização educativa da sociedade civil, a essa luz, abandona o terreno mítico das idealizações e reconhece, com Otayek, que "A virtual incivilidade da sociedade civil recomenda, pois, que seja afirmada a necessidade da reabilitação do Estado" (2000, p. 129), na dupla função de agente regulador do associativismo e de fornecedor de incentivos e recompensas às organizações da sociedade civil que se vinculem a uma agenda educativa orientada para um desenvolvimento concebido como cultivo da humanidade nas circunstâncias preocupantes e desafiantes do presente.

A forma como isso pode ser feito sem comprometer, em demasia, a autonomia organizativa da sociedade civil é algo a se ponderar e a se decidir no seio de uma democracia deliberativa, também ela à altura dos desafios e das preocupações atuais. 


\section{Education and development: cultivating the humanity in the areas of civil society}

\section{ABSTRACT}

This article, taking as a reference the climate of economical anxiety that Europe is living, revisits the theme of education and development and it argues that civil society, through its institutions and organizations, can play an interesting role in the promotion of one other development, not properly as a recurrence in the increase of gross domestic product and the utilitarian view of people, but as the cultivation of a humanity that is facing today alarming challenges in the areas of governance, culture, human rights, justice and relations with the environment.

Keywords: Education. Development. Civil society.

\section{REFERÊNCIAS}

APPIAH, Kwame. Cosmopolitismo. La ética en un mundo de extraños. Buenos Aires: Katz, 2007. . Mi cosmopolitismo. Buenos Aires: Katz, 2008.

BARBOSA, Manuel. Educação e cidadania. Renovação da pedagogia. Amarante: Labirinto, 2006. A educação em arenas sociais multiculturais. Revalorização do papel da sociedade civil. Revista Teoría de la Educación, Salamanca, Universidade de Salamanca, v. 23, p. 151-170, dez. 2011. BAUDRILLARD, Jean. La société de consommation. Paris: Denoël, 1970.

BECK, Ulrich. La mirada cosmopolita o la guerra es la paz. Barcelona: Paidós, 2005.

BECK, Ulrich; GRANDE, Edgar. La Europa cosmopolita. Sociedad y política en la segunda modernidad. Barcelona: Paidós, 2006.

CAMPS, Victoria. El declive de la ciudadanía. Madrid: PPC, 2010.

COMISSÃO EUROPEIA. Governança europeia. Um livro branco. Bruxelas: Comissão Europeia, 2001. . Estratégia Europa 2020. Bruxelas: Comissão Europeia, 2010.

CORTINA, Adela. Hasta un pueblo de demónios. Ética pública y sociedad. Madrid: Taurus, 1998. DOBSON, Andrew. Ciudadanía y medio ambiente. Barcelona: Proteus, 2010.

GUTMANN, Amy. La identidad en democracia. Buenos Aires: Katz, 2008.

KALDOR, Mary. La sociedad civil global. Una respuesta a la guerra. Barcelona: Tusquets, 2003. KEANE, John. A sociedade civil. Lisboa: Temas e Debates, 2001.

LATOUCHE, Serge. La voie de la décroissance. Pour une société d'abondance frugal. In: CAILLÉ, Alain et al. (Eds.). De la convivialité. Paris: La Découverte, 2011. p. 43-72.

LAVAL, Christian et al. La nouvelle école capitaliste. Paris: La Découverte, 2011.

LAVILLE, Jean-Louis. Politique de l'association. Paris: Seuil, 2010.

LIMÓN, Dolores. Ecociudadanía: participamos en democracia con un compromiso ético ambiental. In: BOLÍVAR, Antonio; GUARRO, Amador (Coords.). Educación y cultura democráticas. Madrid: Wolters Kluwer, 2007. p. 94-115. 
NUSSBAUM, Martha. Las fronteras de la justicia. Consideraciones sobre la exclusión. Barcelona: Paidós, 2007.

Katz, 2010.

Sin fines de lucro. Por qué la democracia necesita de las humanidades. Buenos Aires:

OLVERA, Alberto (Coord.). Sociedad civil, esfera pública y democratización en América Latina. México: Fondo de Cultura Económica y Universidad Veracruzana, 2003.

. Identité et démocratie dans un monde global. Paris: Presses Sciences PO, 2000.

OTAYEK, René. A descentralização como modo de redefinição do poder autoritário? Algumas reflexões a partir de realidades africanas. Revista Crítica de Ciências Sociais, Coimbra, Universidade de Coimbra, n. 77, p. 131-150, jun. 2007.

PASCUAL ESTEVE, Josep. El papel de la ciudadanía en el auge y decadencia de las ciudades. El fin del gerencialismo o la recuperación de lo publico y sus actores. Valencia: Tirant lo Blanch, 2011.

PEDRAJAS, Marta; JORDAN, Josep. Políticas en pro de un desarrollo humano. In: CORTINA, Adela; PEREIRA, Gustavo (Eds.). Pobreza y libertad. Madrid: Tecnos, 2009. p. 211-234.

PÉREZ-DÍAS, Víctor. El malestar de la democracia. Barcelona: Crítica, 2008.

PIROTTE, Gautier. La notion de société civile. Paris: La Découverte, 2007.

PNUD. Relatório do desenvolvimento humano. Lisboa: Mensagem, 2003.

PRADOS, María; CALIXTO, Pilar. La evolución del concepto de sostenibilidad y su incidencia en la educación ambiental. Teoría de la Educación, Salamanca, Universidade de Salamanca, v. 20, p. 179-204, dez. 2008.

REQUENA, Félix. Redes sociales y sociedad civil. Madrid: Centro de Investigaciones Sociológicas, 2008.

ROSANVALLON, Pierre. La société des égaux. Paris: Seuil, 2011.

SASSEN, Saskia. La ciudad global. Buenos Aires: Eudeba, 1999.

SEN, Amartya. Temas claves del siglo XXI. In: SEN, Amartya; KLIKSBERG, Bernardo (Eds.). Primero la gente. Barcelona: Deusto, 2007. p. 13-117.

SEN, Amartya. A educação como desenvolvimento. Lisboa: Gradiva, 2003.

TEJERINA, Benjamin. Movimientos sociales, espacio publico y ciudadanía. Los caminos de la utopía. Revista Crítica de Ciências Sociais, Coimbra, Universidade de Coimbra, n. 72, p. 67-97, jun. 2005.

TODOROV, Tzvetan. La peur des barbares. Au-delà du choc des civilisations. Paris: Robert Laffont, 2008.

UNESCO. Década das Nações Unidas da Educação para o Desenvolvimento Sustentável: Documento Final. Brasília: Unesco, 2005.

WALZER, Michael. Política e paixão. Rumo a um liberalismo mais igualitário. São Paulo: WMF Martins, 2008.

. Pensar politicamente. Barcelona: Paidós, 2010.

WARREN, Mark. Que tipo de sociedade civil é melhor para a democracia? In: VIEGAS, José; PINTO, António; FARIA, Sérgio (Orgs.). Democracia. Lisboa: Celta, 2004. p. 85-97. 